Michotte is concerned with), when one billiard ball strikes another, we see the second ball move off as a result of the blow. We see this not intellectually, but as a direct perception, like seeing the colour or shape of an object. His basic demonstration is simple and elegant: it involves pairs of coloured patches, arranged to move so that the first approaches and touches the second, which then moves. In a long series of experiments, the velocities of the two coloured patches are varied, and a delay is sometimes introduced before the second patch moves off. The effect with some velocities and delays is truly striking - one could swear the first patch pushes the second. In other conditions it seems to 'launch' the second pateh, or again to 'project' it. Indeed, a language for describing the effects has grown up, and in this we seo something of the strongth and the weakness of the experiments. If there were no clearly different perceptual effects under the various conditions, it would scarcely have been possible for such a language, commanding reasonable agreement from naïve observers, to have developed; but just because it has developed, there is probably a tendency for the language to over-classify and modify the perceptual experiences.

Whenever experiments involve various conditions of stimulus but rely on descriptive reports, we are somewhere in an uneasy hinterland between science and art criticism, and it is extremely difficult to evaluate the results or place much confidence in the details. This does make one wonder whether Michotte was altogether wise in pursuing his first elegant demonstration with quite the thoroughness evident in The Perception of Causality. Would he not have done better to abandon verbal reports of this descriptive kind, in favour of getting his observers to compare their perception of his moving patches with other things? In particular, one would like to know whether the time and velocity relations over which causality is 'seen' is tho same for the neutral patches as for real billiard balls. Would the critical conditions be the same for expert billiard players, or engineers, as for those naive in matters physical ? Such comparisons might give a more convincing answer to the question of how far the perception of cause is learned.

We are subject to Michotte's causal effects whenever we see a cartoon film: Are wo subject to them watching normal films, and dealing with the physical world? How far do we tolerate queer behaviour in real objects, and still see cause? It should be possible to find out, and who better than the workers at Louvain to tell us.

R. L. GREGoRY

\section{A MONUMENTAL PSYCHOPATHOLOGY}

\section{General Psychopathology}

By Karl Jaspers. Translated from the German 7th Edition by J. Hoenig and Marian W. Hamilton. Pp. xxxii + 922. (Manchester: The University Press, 1963.) 75s. net.

HIS book has been regarded as one of the classic

texts of German psychiatry, a reputation it acquired soon after its first edition was published fifty years ago. Re-reading it after many years, one is again struck by the wealth of material presented, the clearness with which individual problems are scen and the beauty of the clinical descriptions.

The author divides his book into seven parts: introduction; individual psychic phenomena; meaningful psychic connexions (verstehende Psychologie); the causal connexions of psychic life (erklärende Psychologie); the conception of the psychic life as a whole; the abnormal psyche in society and history; the human being as a whole.
To me it seems that there are three main ways in which the author's work can be elassified: phenomenology; methodology; philosophy.

In psychiatry he has probably been best known for the phenomenology. This is partly due to the outstanding description of patients' experiences and behaviour, but of even greater importance is the differentiation of the observed phenomena. As an example of this I should like to quote his dealing with feelings and affective states. $\mathrm{He}$ describes the changes in bodily feeling, changes in feeling of capacity, apathy, feeling of having lost feeling, changes in feeling tone of perception, unattached feelings and, finally, the growth of private worlds from unattacherl foelings.

In the same way he deals with a largo number of psychological items, be they delusions, hallucinations, speech, use of symbols, intelligence, memory or others. Probably the best are his deseriptions and classification of hallucinations and delusions. Concepts like the 'primary delusion' or 'delusional perceptions' are exemplified and deseribed. Linguistic difficulties may in the past have been responsible for the fact that these ideas were rather ignored by British and American psychiatrists.

Constitution and heredity, physiognomy and handwriting are among the numerous aspects described by Jaspers, but among the most impressive is the author's way of dealing with the individual's personal world, especially the world of the schizophrenie, of the obsessional and of the manic patients.

Methodology is frequently discussed. His criticisms of authors like Freud and Kretschmer on grounds of faulty method are often illuminating, although not always original. About 25 pages are devoted to the nature of theories, their formation and his own critical attitude to theorizing. His view that theories have only a limited value as they tend "to suffocate real insight. lively observation and all scientific progress" makes him a true phenomenologist, although he disagrees with this view of himself in the preface of the seventh edition.

The author's philosophical stand is existentialist and this pervades the book in spite of his warning that existential philosophy cannot be used "as a means of aequiring psychopathological knowledge".

In the introduction written in 1959, Jaspers admits that during the past two decades his book has not been brought up to date and yet claims that it is not out of date. While this is in essence true, it seems regrettable that most research done outside Germany is ignored and that there is an almost complete absence of references to work done in the past twenty years. Kretschmer's theories are discussed on 18 pages, but Sheldon is not mentioned. In the chapter on heredity Mendelian theories are summarized, but Kallmann, Slater, Ponrose and the Scandinavian School are not referred to. The treatment of general paralysis of the insane is stated to be inoculation with malaria. These are blemishes on a great work. They should not be regarded as detracting from its exceptional value. Wo owe a debt of gratitude to the Department of Psychiatry of the University of Manchester for this translation, which is a remarkable rendering in English of an extremely difficult German text. This is a very commendable achievement, as Jaspers's writing is far from easy and he often invests some words with a rather special meaning. One error surprised me. The German term Amentia is rendered as 'amentia' in the English text, but Amentia in German means an extreme state of confusion, while 'amentia' in English means mental deficiency or sub-normality.

I myself think that an abridged version containing mainly the phenomenology would be of immense value, as the size of this book as well as the philosophical parts will cause some potential readers to shy away from one of the more important fundamental contributions to psychopathology and to psychiatry.

S. L. LAST 